\title{
ARCHITECTURE-INSTRUMENT: THE ARCHITECTURE-MACHINE ORIGINS AND FRAMEWORKS OF MACHINIC LINE OF THINKING IN ARCHITECTURE
}

\author{
DOI: 10.18485/arh_pt.2020.7.ch54
}

\author{
_ Dragana Ćirić \\ PhD, dragana.ci@gmail.com
}

\begin{abstract}
The paper will aim to introduce the format of the architecture-instrument as a specific spatial model for the converged architectural artistic and scientific design research and practice. This will be performed in relation to its machinic origins or counterparts - since this form constitutes itself through different concepts of the machine variously present, applied and interpreted throughout the history within and adjacent to the architectural discipline or field of interest depending on the historical period, different machinic modalities and their attributes will be the central concern of the study. Architecture-machines will be analysed in line with several criteria alongside the additional aim of tracing its genealogy and categories. Therefore, the long present machine paradigm in architecture will be challenged toward its contemporary reassessment within which possible lines of development and major features of the architecture-instrument could be inferred against the chosen references and theoretical notions.
\end{abstract}

The experimental prototype exo that claimed the status of the architecture-instrument in its most advanced form - integrating sentience, algorithmic control and automation, kinetic properties, adaptability, intelligent responsiveness and interaction concerning the tracked objects, systems and environmental parameters - while also attempting to redefine and question its epistemological, methodological and technical implications, will be used as a case study that has tested some of the proposed claims, providing thereby necessary empirical evidence for the arguments. The analysed examples and sources will establish a clear outline and framework of the machinic line of thinking in architecture, enabling one thus to discern and better understand the architecture-machine/instrument's semantic scopes, applied forms, constitutive properties and importance along with the disciplinary and scientific-artistic integration they imply in the current moment as a continuation of its much longer traditions.

KEYWORDS _ architecture-instrument, architecture-machine, machine genealogy in architecture, design research science and methodology, disciplinary convergence

\section{INTRODUCTION}

In its initial statement, the first prototyping phase of the global eye(s) project - exo experiment - theoretically challenged previously widely used concept of the architecture-machine which has been planned to deliver the proof of the concept and start the development phase of the technical solution for the proposed architectural integration. The form of the architecture-instrument has been presumed as the architecture-machines's refined modality, better suited for the investigative and testing objectives in this particular situation, converging thereby all the models which already existed in literature and practice in line with its own criteria and specific aims. The reason why the 
existing forms haven't been just adopted are all those fine differences in their definitions which couldn't have been neglected and whose subtlety has been important for the maintenance of the richness of architectural formal capacities and vocabulary. Besides the machine and its modalities (device, mise-en-scène machine and installation (Wihart, 2015:110-118), architectural model as machine (Smith, 2004), mechanical, cybernetic, mathematic, state-machine and heterogenetic machine (Broeckmann, 2016:19-28)), the instrument, prototype and prototyping model, analogue model, performative model (Stojanovic, 2013) and simulation (Kolarevic, 2003, in Stojanovic, 2013:8) were all taken into consideration. This project has been drawing features from all of them, qualifying to be designated by each term except for those having passive properties (such as architectural scale model). But, if identifying with any of them alone, the opportunity of displaying the nuances that were posited by its initial concept or further documented throughout its strategic planning and realisation, would be at risk. Hence the principal theoretical analysis follows the question of the format elaborating on introduced machinic concepts. The primary references address the notion of the "machine", both mechanical (kinetic, tactile) and conceptual (virtual/abstract). The questions of how these notions influenced and shaped or could be transformed into or replaced by the "instrument" along with the requirements that should be fulfilled to justify such transition, will lead to main conclusions. One will be able to see how boundaries between certain aspects or categories of different "machinic entities" easily blur before the design integration approach.

When appearing in the text, the aspects of the exo experiment will serve as supportive arguments to critical observations on principal attributes and key concepts that make up the identity and the class of objects of the architecture instrument and/or machine. It will serve to demonstrate the legitimacy and importance of these forms for architectural design research and experimentation.

\section{ARCHITECTURE-MACHINE AND ARCHITECTURAL MECHANISM: TOWARDS THE FORM OF AN ARCHITECTURE-INSTRUMENT}

The principal section of the paper will try to elucidate the historical lineage of machinic concepts, models and representations with architecture as the central field of interest. The references will span all the fields that have significantly contributed to their development and various applications taking into account more complex integration of different research areas, as well as scientific, artistic and technological convergences and collaborations. Aware of the scope of such an idea, this review will probably have to leave out some examples since the topic is rather demanding and requires significant investigations, especially regarding the time-period and literature it needs to cover. Therefore, it will be designated as an outline of the possibly more detailed future project performed especially for the purposes of the main architecture-instrument hypothesis. The complexity of the historical evidence preceding the first modern interpretations of the concept as well as that of the official machine age (the period that has proclaimed its machinic status - clear machinic conceptual intentions and further convergence of machines and architecture) - demand a more elaborate study. Still, the most distinguished examples will be analysed to support the effort of tracing the machinic continuity and influences in architectural ideas and the proposed classification. The technological progress of societies and their productive capabilities are seen as an important framework predominantly shaping those certain kinds of machinic models that will be discussed. Their succession has been presumed to have led to the form of an architecture-instrument the way one can use it in the current moment but also to the specific articulation of the autonomous line of development of the instruments themselves within the machine genealogy. Hence historical progression of time along with typological clustering and specific architectural operationalisation of the machinic concepts will direct the way the architectural machinic ideas and technical solutions will be presented (Fig.2). The next lines are going to inquire into the evidence and possible arguments in support of the presented claims within the important historical, methodological and epistemological foundations of the converging fields of engineering, architecture, arts, sciences and technologies. 


\section{Theoretical Framework, Historical References and Classes of Machine-Architecture Forms}

Michael Wihart's claim that the history and theory of the "architectural machine" have yet to be written (Wihart, 2015:57) could be agreed with. No such comprehensive work has been provided by any previous architectural study while contemporary research in the field still inscribes its own contributions in the course of the current experimentation. Nevertheless, an important start has been made with his proposal of the "first comprehensive history and theory of architectural machines" (Wihart, 2015:53) the way he defines such ambitions of the chapter addressing the issue. Wihart provides a brief overview of the selected historical constructs from different scientific areas proceeding with observations on the experiments from the early and late modern period, technocratically enhanced mid-20th century and the second half of the 20th century, concluding everything with the emergence of soft (machinic) paradigm, the current soft architectural robotics and digital control which his own investigations have been based on. He manages to cover the machinic concepts and sources closely related to the architectural field which few more examples could be added to, mostly those developed within different disciplines (such as, for instance, in arts (Broeckmann, 2016), philosophy or history of science) or in historical periods that weren't so elaborately inquired. After the references to Vitruvius as the most featured representative of the ancient period and most frequently translated, Wihart decides to put the focus on the 16th century and the period of Enlightenment by recognizing their particular significance for the rise of the mechanical paradigm (Wihart, 2015:59) based on then posited laws of mechanics and development of various technical solutions in line with thereby developed formulas. To that analysis, one can certainly add the publications such as Picturing Machines 1400-1700 (Lefevre (Ed.), 2004) or II Teatrum Instrumentarum et machinarum (Besson, 1582) and a series of singular articles arguing on the theme (e.g. Scaglia, 1966; De Gandt, 1986; etc.) as volumes that draw on the examples that weren't given sufficient attention by Wihart. They adduce convergences or close relationships between the architecture and machinic solutions from earlier historical periods (including Aristotle, Archimedes, Heron, Pappus, Ctesibius, Vitruvius, Hero, Boethius, Brunelleschi, Da Vinci, di Giorgio Martini, and others; Scaglia, 1966:90-114; Lefevre, 2004), continuing with mathematically refined explanations of mechanical problems and their precise scientific framing during the 17th and 18th century (based on the studies of Galileo, Leibnitz, Newton, Descartes, Laplace, and others) which Wihart gives emphasis to. The engineering, mechanical and structural line of development of architectural ideas, investigated in the author's previous studies (Ciric, 2017), represents a helpful complement to the list of sources, while among the new publications from the last couple of years Wright Steenson's Architectural Intelligence represents an invaluable record on the cybernetic period in architecture whereas Broeckmann's The Machine Art in the Twentieth Century reveals an important perspective on the way the subject has been interpreted within the artistic discourse and practices.

Throughout history, there has been a number of mechanical solutions related to different kinds of spatial or building interventions. Not all of them have been directly aimed for architecture, but those applied in architectural design implied either influence on building techniques, typological and programmatic transformations, narratives and functions, or integration of innovative systems into the design logic and processes. One can distinguish several modes in which mechanical or machinic (both "soft" and "hard") designations in architecture appear. This classification is based on the embeddedness of the machinic features in architectural structures and systems, and on the level (or a scale) of the machine-like presence in architectural objects. In other words, the criteria refer to the existence of either replaceable mechanical components or complete machinic integration (a total equivalence of the architecture and the machine) and to the level which the machinic concept has been applied to. The latter distinguishes 1. a component and element - the part and detail of an object having mechanical properties, 2. the system and logic where mechanical procedures are used either as the concrete technical solution (the logic of systemic networking) or as an analogy (whereas analogies might be designated as false mechanical concepts based on association rather than real machinic properties, or as concepts of the abstract machines - mindsets and structures), and 3 . the whole object assigned with full integration without the possibility of being separated from the machinic features in any way. Integrative and systemic approaches directly influence and 
control the very design process entering into its logic from the conceptual start, while the use of mechanical components as autonomous elements implies certain flexibility regarding both their inclusion in development stages of the project and the possibility of their refinement or replacement in various stages.

Following these criteria, one can try to identify the more precise set of categories of architecturemachine convergences. The first one refers to mechanical interventions applied on a smaller scale providing therefore mobility of architectural elements based on specific architectural detailing or more complex structures that enable kinetic maneuvering. They range from the simplest sliding, rotating and revolving functions of architectural elements (doors, windows, walls, roofs) to theater props, mechanical scenographies or audience constructions. It draws some origins from the ancient mythological interpretations of the mechanic-craftsman-architect contained in the character of Daedalus and its ability and power of making objecthood interpretations of the invisible and abstract dynamics, or daidala - i.e. machines, automatas (Smith, 2004:40-49). The second recognizes the use of machines as facilitators of architectural design and execution tasks (machines as devices used in either drawing and design processes or in building processes), and specific use of machines involved in the construction of the visual reproductions (from the first visualising techniques of drawing, painting and sculptural $3 \mathrm{~d}$ modelling, across the first vision machines, aerial reconnaissance photography and film, to the contemporary machine vision based on multispectral analysis and other artificial visual systems). The objects that could be assembled, reassembled and disassembled according to the requirements, represent the third form also dependent on the specific design of mechanical components and detailing. Here fabricating methods become essential for the acquisition of the machinic features as well as automation and software integration in self-assemblies. The category also traces the leap from constructivists' to deconstructivists' ideas having reconfiguration and self-reconfiguration alongside the forces that cause them, at its basis used even as the abstract design principle (e.g. Denari's or Woods' "machine-architectures as a destructive/deconstructive or technomorphic force"; Wihart, 2015:83-84). Finally, there is a total integration proposing certain smoothness of architecture-machine synthesis (inclining either towards a kind of biochemical integration (soft kinetics) or indicating the electronic and sentient control of spatial systems - architectural embeddedness in systems of pervasive computing). The last category is largely present in experimental forms of installations and prototypes while also implying various applications on larger scales (in objects, architectural and urban systems, or on the planetary and cosmic level).

Machinic attribute usually introduces dynamics into static architectural forms or provides certain kinds of animation to the initially inanimate objects. Dynamic properties work as input information conditioning further the performance, some inner principles or a narrative of the constructed object. Historically, in some of the first machinic examples natural dynamics such as astronomical or meteorological occurrences, have been embedded into the architectural settings as a time component or the means of the time measuring, official ordering and organization of daily lives as well as for the integration of some higher natural principles into the architectural language and creation of symbolic meaning. Reflected in architectural ideas, celestial dynamics for instance - mechanical movement derived from the "revolution of the heavens/heavenly bodies" - created some of the first astronomical and time machines, the cosmic machines as not only "mere expediency but a symbol of the universe as well" (Jormakka, 2005:7). Jormakka mentions Marcus Terentius Varro's aviary with the dome that slowly revolved on the inside corresponding exactly to the sky, thus functioning as a clock, the patent that has been later applied in Nero's Domus Aurea and Villa Adriana's Teatro Marittimo. One finds such examples in numerous architectural objects, ensembles or elements. Among the many that have used such environmental and symbolic parameters (Ciric, 2017:71-80) are the pyramids in Giza (Magli, 2009: 35-50), the whole complex of Hadrian's villa in Tivoli (Caliari 2012), Pantheon (Spelling, 2015: 220-223, 225), Augustus' Horologium in Rome and many other less analysed singular examples of religious and important public buildings as well as their urban and territorial networks, architectural complexes and the whole urban matrices (urban design as cosmo-geometric logic in Rebelo Paio, 2009:70). Designed to reflect the astronomical, civil or ec- 
clesiastic time and time metrics related to daily functions and activities (Monti, 2010:80-115), these objects engineered synchronisation of the natural, social and biological rhythms. From the Renaissance on, observation practices and architectural programmes subsequently recorded notable advancement in the development of the scientific instrumentation that was more and more becoming the integrative part of the architecture. Modern era observatories with new models of telescopes, machine technologies and their mechanisms, manifested new architectural mechanical models, specific kinetic domes, rotating floors and ceilings. Large mechanical systems housed within the space - the sliding opening/closing systems, the rotating mechanisms and kinetic elements that bear loads of the observation equipment - merge with the specific construction systems and their design processes and solutions, rendering architecture's machinic character. This type of architectural buildings evolved along with the development of observational technologies and has been present as "machinic" architecture all the way to its current forms (reviewed in Leverington, 2017). Today they can take different courses and forms instigating the emergence of new architectural typologies or enhancing the existing ones. The measuring instruments are not only housed within the architectural space but become architecture themselves - a real integration of architecture and instrumentation whether objecthood or digital. On a larger scale, such objects-instruments become nodes in the networks of data transmission, observation and information systems (Easterling, 2014:16, 119, 134; Kitchin and Dodge, 2011) and part of new machine landscapes (Yang, 2019:6-13). Machinic features related to military engineering, architecture and design represent a historical commonplace. Starting with the machines that have served as building and measuring instruments enabling proper geometry of a building (fortification) and its accommodation to landscape (Di Gorgio Martini; Cataneo; De Marchi in O'Donnell, 2013:47-59; Henninger-Vos, 2004:143-169), the forms that have informed architecture in this way, either as its integrative constructive mechanical parts or a means of its destruction, evolved into real architectural war machines. Dependent on their capacities, both constructive and destructive, architecture reflected the results of their influence and integration. A destructive threat (and its measure) which architecture had to withstand has been formative for the attribute of the architectural resistance. It shaped and steered design and choices of architectural elements, building techniques and materials. Moving machines (siege engines) for breaching into the adversarial installations represented one of the examples that architecture had to respond to properly as to all alike perilous external forces but it also represented their source of design and construction guidelines since some of them closely resembled more permanent architectural objects. Vitruvius' mobile war machines, mechanical devices based on water and air power and construction machines (X Book) along with time machines (IX Book) are just some of the first machinic kinetic designs of the ancient period one usually refers to while investigating this class of objects. Even though the number of machines he represents were adopted from numerous predecessors, the fact that he compiles them as a part of the architectural volume or for the purposes of the architectural education shifts their principal field of reference and application. Following his famous statement that "the body of architecture consists of three parts: buildings, clocks and waterworks" (in Jormakka, 2005:7) two of which are essentially machinic, mechanical skills and knowledge were placed within the architectural field of competence. Instruments used in building and engineering, territorial survey and measuring, became major architectural equipment and part of the architectural arsenal of tools implying additional training within the profession.

First machinic solutions in ancient architecture are also found in theater buildings and the design of their components (rotating parts of the audience, platforms and stage props). Lots of them have been significantly changed only with the modern period and contemporary technological innovation. Proposals for the total theater (Gropius, 1927), Friedrich Kiesler's design for an endless theater and the R.U.R. stage set, or László Moholy-Nagy's design for kinetic construction (1922) based on mobile structures and his theory of the dynamic-constructive system of forces (Moholy-Nagy, 1947 in Wihart, 2015:78), are only some of the examples. Following thus presented new design methods in the long tradition of the class of theatrical settings, the extensions within the typology in the form of temporary event architecture, including exhibition and experimental pavilions at different International Exhibitions, added to its range of possibilities for architectural mechanical expression and 
experimentation. A significant contribution to machinic genealogy in architecture, considering both mechanical and electronic integration, has been thus assigned to proposals introduced through these forms. The cybernetic and information turn got inscribed through exhibition proposals for the Brussels, Montreal and Osaka Expos (e.g. E.A.T.'s Pepsi Pavilion, Arata and Kurokawa's robotised event system for Festival Plaza and the whole concept of the Model City of an Information Society) while the latest projects based on transformative structures and spatial assemblies - adaptive and performative experimental spaces - imply, perhaps, more tenable mechanical settings (e.g. OMA's Prada Transformer (Lipson, 2011:22-23) and MPavilion, or Diller Scofidio + Renfro's Shed reflecting on Fun Palace's transformativity, responsiveness, flexibility, deployment of gantry crane technology and rail tracks).

Machines had a large impact on basic spatial organisations in line with industrial upheavals that instigated their advents. Their influence on residential architecture comes as another proof. For instance, the whole typology of skyscrapers with extensive efficient vertical stacking and movement became possible only due to the specific use and new patents of elevators. Villa Girasole, Invernizzi (Carapacchi and Fagiuolli, 1929-1934) and La Casa Girevole (Pier Luigi Nervi, 1934) used mechanical systems from the industrial domain to include the movement (rotation) into their spatial concepts. A direct concept of the architecture-machine has also emerged (Le Corbusier, 1923). Le Corbusier's famous modernist's fascination with industrial production and engineering rationality, movement, automobiles, airplanes and ocean liners, became canonic. As seamless continuity of the scientific engineering convergence with architectural discipline from the previous epoch, and consequent appraisal of the mobility, progress and machines in futurism, their moderate and humanized position came as one of the outcomes. The traditions of the rationalistic thought and scientific approach in French architectural theory and practice and its progressive engineering line emerging as a consequence of industrialization (Rondelet and Blouet, 1812-1814; Viollet-le-Duc, 1863-1872; Picon, 1992, 2014) got its altered and refined continuity in Le Corbusier's writings, designs and public statements in support of the new architectural and social ideology (new spirit) following the internationalization, second industrial revolution, rapid production and standardisation. The noted concept of the machine, however, hasn't been used to designate the architectural object in a literal sense, but rather reflected social, technological and cultural conditions that shaped and ordered these entities and the life within representing it as a completely mechanized activity. It worked as a metaphor coming from assembly lines and mass-production, the new ordering of time in everyday life and practices that all now had a kind of machinic (automated and repetitive) properties. The machine represented the system - the way of thinking, living and production - and as such functioned as a constitutive environment for attitudes inclining towards the rational and efficient solutions relying on new design approaches of engineering science and new building techniques. It represented the logic of a perfectly tempered mechanism of normative thinking which all the living organisms, qualities and programmes could have been subjected to. The attribute of being functional or operative as a machine worked in two ways - the first regarding building processes that "machinic logic" made more effective and efficient; the second referring to the programmatic aspects - functionality and operation inside the finished object referring to daily activities and performances as precisely controlled social and natural rhythms. The machinic attribute also referred to new equipment - the real machines included in the spatial programmes such as vehicles, kinetic elements like elevators, mobile sliding walls and windows, and home devices.

While the early modern period had airplane and automobile industries in the background of its machinic metaphors and applications, and space sciences were still entering the industrial realm, the next phase of machinic development has been focused mostly on digital systems and cybernetics. The noted "technical transformation from a mechanical to computer-based machine paradigm..." (Hultén in Broeckman 2016:94) implied the focus on the development of autonomous machine systems and software-controlled processes, those that transferred decision-making from humans to machines. The transition from hard to soft steering marked the "end of the mechanical age" (in reference to "The Machine at the End of the Mechanical Age", 1968 and Banham). The notion of the "machine" in the coming years and cybernetic explorations, according to Broeckman, traced 
two meanings (Broeckman, 2016:95) - the mechanical/physical and mathematical/conceptual. The first one represented a continuity of the classical technical apparatus in which "machine" still had material properties, construction and now electronic integration, while the second one interpreted "machine" as "conceptual device that could have been modelled in mathematical formulas or algorithms..." (Broeckman, 2016:95) dealing with mathematical processes that define performances and operations but also representing the logic of thinking. These two concepts haven't been opposed to each other, nor devised to replace one another, but used in a way that "blurred a distinction between the physical and conceptual notion of the machine" (Broeckman, 2016:95). In other words, the machine's inner logic and "thinking" or controlling component (its brain) and its physical configuration have been integrated. Cybernetic science also aimed at blurring the perfect boundary between the living and mechanical worlds, the humans and the machines. It used biological systems as models for artificial counterparts, while the artificial systems worked as devices of human enhancement. The awareness of the unprecedented primacy of artificial systems in some areas and evident difficulties with certain tasks in others while being in constant competition with human organisms, incited new questions. The difference between the analytical power and more complex sentient and experiential power came with the apparent underscores for the artificial systems in the second one. This has, however, significantly changed in favour of the machines with recent advancements in sensory technologies - modules and devices that can emulate human sensorium but more importantly go beyond the human sentient abilities. The latter refers to multispectral reconnaissance which has made every signal outside of the optical window and outside of the human hearing range sentient for the machine (through UV, IR, X-ray, gamma-ray, radio, infrasound and ultrasound sensors) - precisely the kind of the technological convergence designed for the exo's performance. With the latest machine learning algorithms, machines are approaching the challenge of being "superhuman" on all levels.

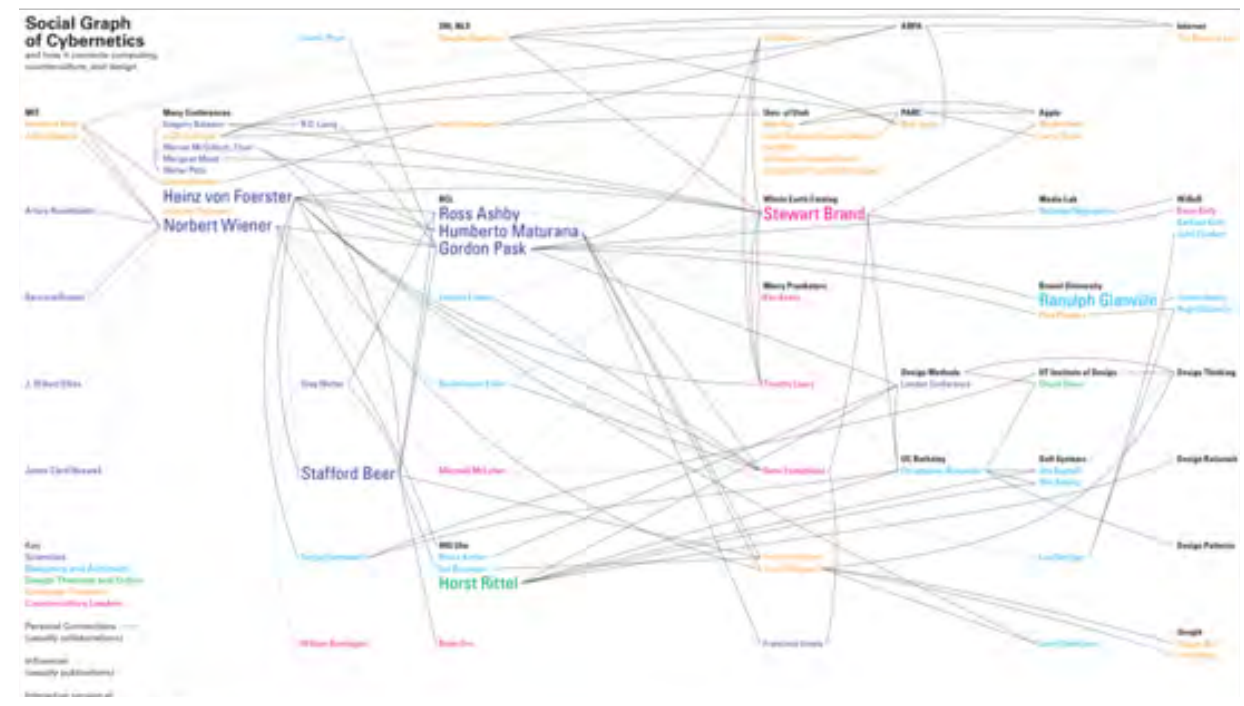

_ Figure 1: Social Graph of Cybernetics and how it connects computing, counterculture, and design, Hugh Dubberly and Paul Pangaro, 2015 (also published in Dubberly, H. and P. Pangaro. (2015) "How cybernetics connects computing, counterculture, and design". In Hippie Modernism: The Struggle for Utopia - Exhibit Catalog, Walker Art Center, pp.1-12; diagram, pp. 2-3)

The commented period of these first abstract electronic and mechanical machines has been made possible based on, not only cybernetic science but the number of new research fields such as systems theory and complex adaptability, information and computer sciences. They were equally treat- 
ed and investigated in all disciplines that could have had an interest in their application besides those from where they have originated. These fields were mutually highly contagious and supportive, instigating each other's progress. The experiments that appear in arts, design and architecture, social theory and culture along with information and computer sciences all constructed this new intellectual movement and network.

Within the field of architecture, the influences of the cybernetic, ICTs, systems theory, artificial intelligence and complexity have been more than evident. The new approaches to mobility and adaptability have been proposed by Yona Friedman's 1958 Mobile Architecture Manifesto or Archigram's and Ron Herron's Walking City (Cities:Moving, 1963, 1964, 1968) inspired by space technologies and vehicles designed for extreme environments. Dennis Crompton's Computer City (1964, in Sadler, 2005:21) draws direct influences from monitoring systems and sensory nets acting as the "cybernetic city of control and communication", the city as computer mechanism (Sadler, 2005:120, 121), while collaborations such as those between Gordon Pask and Cedric Price in Instant City project and Fun Palace (Pask having the role of the cybernetic consultant to Joan Littlewood and Cedric Price (Sadler, 2005:216, note 220; Wright Steenson, 2017:129) while John Frazer being instrumental for the computation framework (Wihart, 2015:126-note 205)), stand out as some of the most striking efforts of architects to cope with the new electronic, wireless, remote control and monitoring era. Applied cybernetics and information processing techniques represented the main issues of the $O x$ ford Corner House $(\mathrm{OCH})$ and Generator (Wright Steenson, 2017:5, 134-162) as well. Besides the cybernetic, these projects introduced another machinic feature based on communication and responsiveness. Designated as teaching machines, emulating large intelligent computer/information processing systems which it has been possible to interact with, they have represented distinctive architectural environments both self-learning and human learning systems: "... by designing buildings that worked as computers, multimedia environments and distributed intelligence platforms, [Price] he made it possible to envision what it would be like to learn, play and experience in a computerised world." (Wright Steenson, 2017:5). Price's and Archigram's buildings as first cybernetic, electronic, networked information machine-architectures now clearly stand for the precedents of recent smart and intelligent systemic solutions (objects, cities, regions and the whole planet).

In Archigram's works, the idea of architectural sentience and responsiveness (the architecture that could transform according to the users' needs or different input information accordingly; Sadler, 2005:123) alongside modernism's central preoccupation with communication systems and technologies (including traffic), appears in line with their interest in computing and intelligence as the main condition for autonomous performance, learning abilities and therefore a proper response of designed artificial systems. Archigram directly dealt with the technological scientific progress brought by cybernetics, systems theory and ICT. In group's projects, behind the flashy pop features of the representational and media aspects of their critical statements, there is real knowledge about information and computer networks, while for instance Banham and Independent Group, even though influenced by the systemic fusion of architecture, environment and technology, have been "dismissive about cybernetics and uninterested in computers" with their conception of cybernetics marked as "precomputational" (Broeckman, 2016:101). On the other hand, while looking at the $\mathrm{OCH}$ and Generator as centralised and distributed networking models (Wright Steenson, 2017:134), one can easily infer Paul Baran's organisation of the internet system. Even though Wright Steenson doesn't point directly to this reference, she does draw a resemblance between their functioning and the way today's social platforms (e.g. Facebook, Google) work and collect data (2017:132)), either as monitoring or as learning and conversing mechanisms.

The first ideas of machine-learning that cybernetic architects have proposed in those years (today clearly seen as predecessors of the generative algorithms and neural networks) were taken for a model of the human enhancement and learning as well. They were presumed to operate as learning devices (in the form of the whole environment) thus extending and influencing the human cognitive performance. On the other hand, by taking into account the performances and desires of the visitors, thereby shifting their own attitudes and operations according to them, improving and extending their own data-bases and experiential memory, computers conduct learning processes. They shape their 
behaviour in a given social setting while also predicting the possible future responses and requirements related to participants or "conversants". Based on such computer-environment integration, architecture becomes a real "connoisseur" of the profiles of the people it interacts with, capable of anticipating their behaviour and responding to them properly and autonomously. Teaching and conversing architectural machines were thus artificial cybernetic intelligent responsive and sentient "species" at the scale of the architecture and the living environment that operated as learning and training appliances (both bodily and intellectually).

In support of her architectural intelligence thesis, Wright Steenson distinguishes the works of several architects (Richard Saul Wurman, Nicholas Negroponte, Christopher Alexander and Cedric Price). All of them mark this specific period of information and computer sciences development and entry of architectural interests into their scientific fields (while, conversely, the interest of computer and information engineers and scientists for architecture appears, too (Engelbart in Wright Steenson, 2017:10-11; Minsky in Wright Steenson, 2017:13). Their contribution to the new definition of the machine in the architectural context made a significant shift concerning the existing concepts. Not all of them have directly inquired the very term, but they have provided valuable insights for architectural machinic purposes. The abstract machinic logic which is particularly at stake in this historical period is their main asset. Besides the appearance of the machinic attribute implied by "teaching and conversing machines" from Price's experimental proposals, Negroponte expressed more direct machinic orientation and interests. As the author of the books The Architecture Machines (1970) and Soft Architecture Machines (1975), and the founder of the MIT's Architecture Machine Group (AMG) with Leon Grossier (Wright Steenson, 2017:5, 165-170), later embedded in the MIT Media Lab in 1985, he is one of the most significant figures for the investigation of the architecture-machine concept. His work, centered around the very notion of the machine "contributed to practices which are still considered emergent, including artificial intelligence (AI), machine learning, intelligent environments, virtual reality, remote sensing and drone surveillance" (Wright Steenson, 2017:5). Architecture machine, in Negroponte's terms, stood for his "vision of the intelligent environment that we would all eventually inhabit and that would eventually surround all of us" (Wright Steenson, $2017: 170,172$ ). His interpretation of the machinic environment has been based on an artificial environment's ability for self-organisation and learning. Cybernetic feedback loop and responsiveness of the architectural object/system/environment to certain user requirements, behaviours or external conditions have been widely used in Archigram's projects, but Negroponte will see in these interactive conversations between the machines and humans the possibility of the "system becoming more intelligent over time, by learning from its users and developing in tandem with them..." (Wright Steenson, 2017:9-10); Negroponte will posit the concept we today distinguish as machine learning. Scientific-architectural collaborations between the AMG (Negroponte, Grossier and Bolt) and MIT AI Lab (Minsky and Papert), J.C.R. Licklider, M. Denicoff (Information Systems Programme at the Office of Naval Research), C. Fields (DARPA) and other important figures in ICSs, contributed to Negorponte's success on this matter.

The era discussed by Wright Steenson (1950s-1990s) represents the formative age of the integrative human-machine approach investigating new ways for humans and computers to cooperate "in making decisions and controlling complex situations without inflexible dependence on predetermined programs" (Licklider in Wright Steenson, 2017:177). While investing themselves in this research area, architects were enabled to reconstitute themselves as system architects capable of cybernetically changing their architectural practice (Pask in Wright Steenson, 2017:17). With an emphasis on the design of the abstract layers of space or a design process, this ability could have been applied in two ways - the first by redefining the relation between architects and machinic devices they were using in spatial design, and the second by equating the machine with abstract spatial logic - spatial software (set of designed, self-enhanced and self-reproduced instructions for spatial performance) - that architects themselves were now able to devise and define.

The use of command-and-control technologies for steering mechanical systems or in order to obtain the status of autonomy of artificial intelligence (machinic decision making), has been at the basis of these last-mentioned examples. It is significant to trace how this steering power and log- 
ic has changed from the first mechanical solutions based on row human force or natural power sources, across self-powering and motorized steering to computer control and finally soft kinetic actuation. The most recent stage of machinic development in architecture has been placed along the two tracks. The first represents a continuation of software/algorithmic-controlled architecture - its integration with digital communication, command and control systems whereas the pairing of architectural design with pervasive or ubiquitous computing and different modes of thereby enabled networking, results with different modes of coded space or code/space (Kitchin and Dodge, 2011) and various smart or intelligent technical solutions. The second one follows the biotechnological, biochemical and physical chemistry line, pairing research and theories from these fields with spatial concepts and processes of kinetic actuation (Beesly and Armstrong; Menges; etc.). Operating at the level of atoms and molecules, soft forms of actuation have been supported by the cluster of natural sciences but not without the involvement of information sciences and digital tools as well. The convergences of these two lines incline towards new forms of environmental sensing and responsiveness, determining also the lines of programmable, active and informed matter.

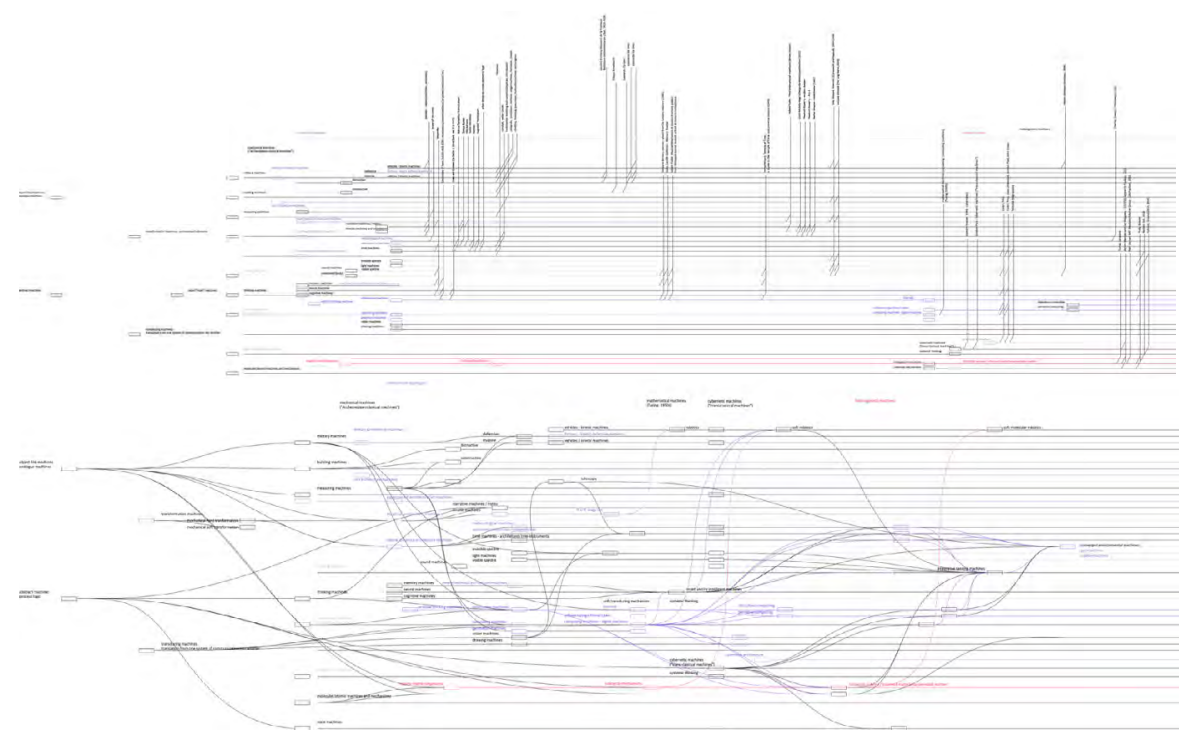

- Figure 2: Outline for a map/diagram of the classification and networking of machines in relation to architecture; D. Ciric, 2020.

While raising the awareness of the role of the algorithmic control and automation in spatial design - the use of coded instructions for designed machinic spatial performance - the notion of the algorithmic architecture-machine came into light. The question of coding literacy, programming or computational thinking and education (Vee, 2017) and the introduction of software studies (Kitchin and Dodge, 2011:13, 246; Vee, 2017) became highly relevant for architecture in line with detected digital turns (first, second digital turn - Carpo, 2012, 2017; Ash, Kitchin and Leszczynski, 2018;.third digital turn - Bava, 2020).

In arts, one also finds a specific line of development of the machinic concept. This is usually a different approach centered around the aesthetic and artistic effects (mechanisms that cause sensations; Wihart, 2015:68-70) and criticality rather than technical skills and procedures deployed as a means towards these ends. In many cases even though technical and technological innovation has been applied, these aspects stay in the background in favour of the overall experience of the artwork, its mode of communication and its poetic, social, cultural, political or intellectual message. Still, such skillful constructions and multimedia integrations, the complexity of thereby created systems, leaves one with firm evidence of technological competences required so as any of those projects 
could have been realised. Referring to historical classes of spatial technical solutions, they resemble the category of artistic assistance to staged events while nevertheless nurturing the role of an individual (an artist) as the one having the major authority over the presented work and the idea.

The book Machine Art in the Twentieth Century by Andreas Broeckmann provides the complete historical overview of the machine concept along with major artistic works that were establishing and confirming its status. In this elaborate study, one finds all the 20th-century art references that dealt with the concept through critical writings, curatorships and practices, and all the external influences that have shaped certain artistic movements and discourses. They have all framed an artistic engagement with technology (Broeckman, 2016: 9-17) inscribing progressive lines of thought and practice within their fields of interest. The collection spans everything from the first appraisals of the machine age and machine art by futurists and constructivists marked by the first exhibitions under their titles (Machine Age in 1927, and Machine Art in 1934 curated by Philip Johnson at Moma), across the Center for Advanced Visual Studies at MIT and its focus on kinetic art, sky art, telecommunications and media, work with lasers, satellites, and innovative materials (Broeckmann, 2016:15,17), to cybernetic, digital and software art. Regarding kinetic experiments, new artworks did rely on its traditions adopting the move from the mechanical towards electronic and cybernetic perspectives - from Tatlin's "machine art" (1915), Alexander Calder's mobiles (the 1930s) or Bruno Munari's playful Useless machines (1930s and 1940s) to Jean Tinguely's dysfunctional machines (1950s and 1960s), Nicolas Schöffer's aesthetic appropriation of cybernetics (Schöffer, in Broeckman, 2016:101) and works of E.A.T. group. The interest for cybernetics, general systems theory, communication infrastructures and sensing technologies in the 1950s and 1960s, constituted a specific artistic register along with its own tools and forms of communication. The Man, Machine and Motion organised by Richard Hamilton in 1955 (Broeckman, 2016:101), 9 Evenings: Theater and Engineering (1966) arguing for the model of artist-engineer collaboration, or the Cybernetic Serendipity (1968) the first international overview inspired by cybernetics and systems theory (Broeckman, 2016:103) are just some among the exhibitions Broeckmann gives emphasis to in this regard. Alongside their curatorial frameworks, he traces two main artistic lines that have, from the current perspective, constituted the main criteria for artistic deployment of named technologies and the definition of the character of the created systems and experiences. These are cybernetic art (Broeckman, 2016:106-108) and system aesthetics - the first evolving from mathematical cybernetics and steering science, the second from ecological systems theory and general systems theory (Burnham, 1968, in Broeckmann, 2016:106, 293)). The three important features one finds in the definition of systems aesthetics for instance - environmental property (blurring a distinct boundary between the artwork and its surroundings or space), interactivity (following von Bertalanffy's definition of a system), and autonomy (both concerning humans as passive or active participants and the ability of autonomous learning and decision making) - define principal attributes by which to evaluate, classify or direct design of the machinic systems even to this day. The last one - a degree of the system's autonomy, the main difference between these two approaches (Broeckman, 2016:107-108) - has been maintained as the most challenging feature and condition of intelligence in systemic solutions. Being centered around the processes rather than complete objects and closed works (Broeckmann, 2016:106) they have also argued for and realised open formats by introducing responsiveness (feedback loops of information used in their systemic integration). Equipped with sensors and software-control enabling interactive protocols between the designed systems and changes in the environment which spectators formed a part of, they have posited another key attribute for the most featured digital or algorithmic art experiments to the present day.

Within the artistic discourse, cybernetics could have been defined as a mode or a framework that enables one to steer artfully towards the goal or to steer towards the artistic goal using different technical devices and inventions (in reference to Pangaro's notions on cybernetics). The "artful control" - in representational and aesthetic registers but also in awareness and problematisation - is that important added value that artistic legacy can offer to all the practically oriented and applied forms of research and experimentation. In this way, the contribution of artistic approaches to scientific rigour confirmes its important share in all the projects trying to converge their areas. 


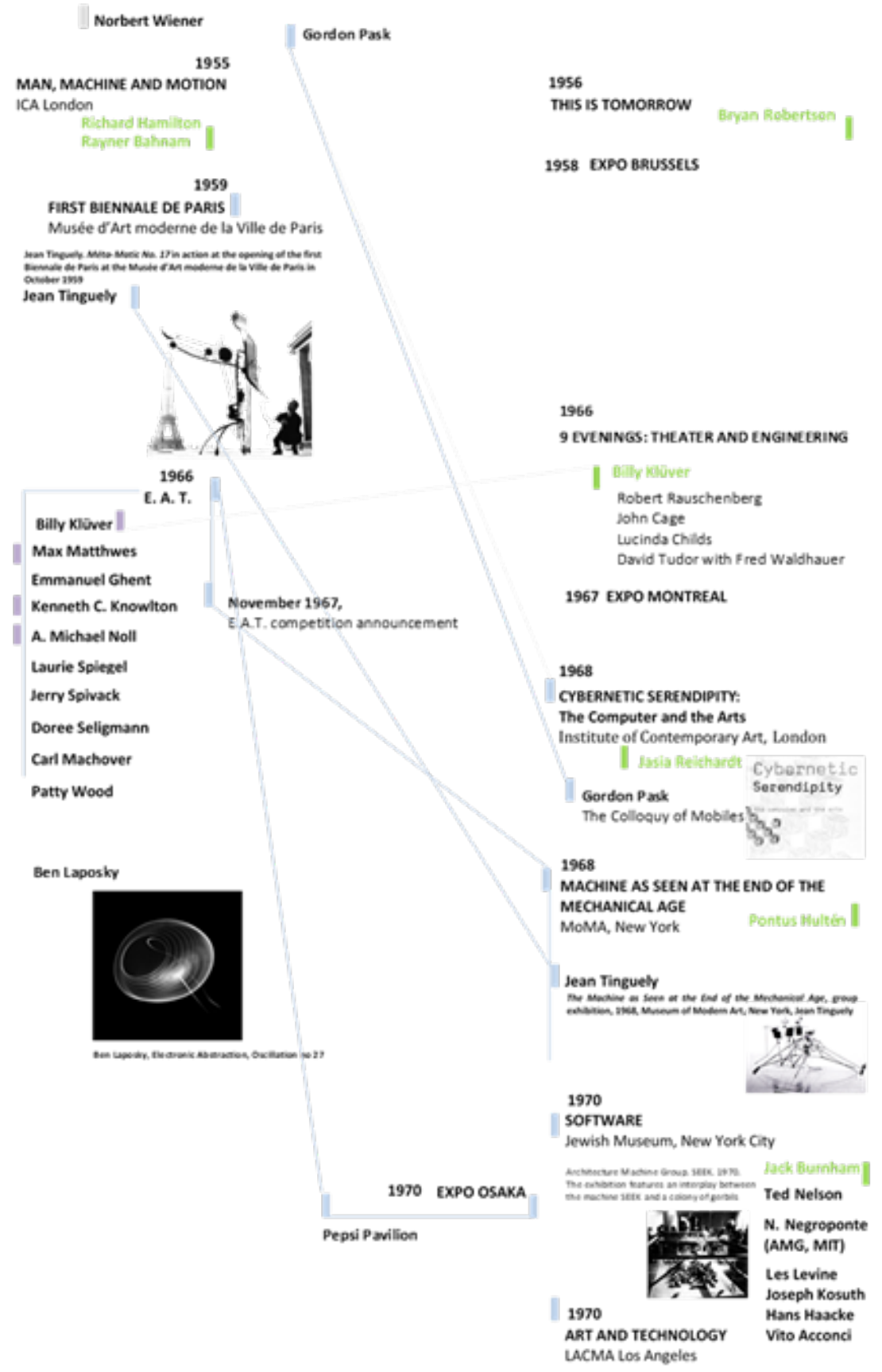

_ Figure 3: Machine art (cybernetic era) - based on the information provided from the publication The Machine Art in Twentieth Century by Andreas Broeckmann) - in relation to additional sources and fields of research: a sketch for a network diagram

Alongside mechanical machine (the machine as an autonomous mechanism, "Archimedean-classical machine"; Gunther, in Broeckmann, 2016:19) and cybernetic machine ("transclassical machine"; 
Gunther, in Broeckmann, 2016:19), Broeckmann adds the concepts of the machine as totalitarian infrastructure (mega-machine, apparatus or state machine; Mumford, 1934, 1967-1970 in Broeckmann, 2016:19-20; also a dispositive, Foucault, Agamben in Broeckman, 2016:28), the mathematical machine (Turing, 1930s), and heterogenetic machine (emerged from the concept of living systems as autopoietic machines defined by Varela and Maturana, from where Deleuze and Guattari derived their understanding of the autopoietic self-production and reproduction of machinic systems; in Broeckmann, 2016:19). He also includes the interpretation of the machine as a "constraint of thought" (Burckhardt, 1999 in Broeckmann, 2016:21) referring to the abstract logic and system of thinking, altogether offering powerful insights in the machine's problematisation. In-between the explanations, the major questions that determine the machine concept have emerged as the main guiding instances - the question of the relation between the machine and human organism, the question who sets the rules of the mechanism or the machine and whether this mechanism is animated from within or from outside the system, as well as those of its degree of autonomy. These questions remained to shape and structure the machinic object by setting the features that qualify certain entities for a machinic designation, whether used in a technical-concrete or a metaphorical [conceptual] sense (Broeckmann, 2016:26).

\section{AN INTRODUCTION TO THE ARCHITECTURE-INSTRUMENT}

When the format of the architecture-instrument has been proposed as a design research model, the number of other forms of architectural experimentation had to be analysed along with the question of the instruments' relation to machines - the hierarchy, overlappings or possiblly autonomous line of genealogy. Taking architecture-machine for an overarching category as the starting assumption, one could have focused on specificities that made more subtle divisions within its domain. Wihart singles out three modes as its common manifestations - device, mise-en-scène machine and installation (Wihart, 2015:110-118). A device implies functional, but passive and closed technical solution; the mise-en-scène machine's "staging for display" and performative tactics - a "theatrical potential of machinic performance" (Wihart, 2015:113-114) - that slightly invade scientific rigour, incline toward artistic application suitable for exhibition performances and simulations, while installation's didactic and investigative potential to test concepts in larger scales and in the form of the real architectural environment could fulfill both scientific and artistic investigative objectives. As the type that outweighs in favour of the scientific method, the prototype model has been added to these options. Its precision, set of procedures, real function and a proper 1:1 scale (implying the correct sizes and proportions of all the modules and elements) coming from the field of the industrial design, formalises and frames the possibilities of the object's technical application. The cluster of architectural models prevailing in passive and representational forms lacks the ability to transform and interact and only their performative models and simulations could make an acceptable substitute when these are required. The absence of functionality as well as scaling will also keep them aside in situations where these demands represent the principal modelling assets. Architecture-instrument, concerning previous comments, introduces additional qualities and subtlety. Differing significantly from some interpretations in which it takes the form of a mere appliance (referring to the notion of instrumentalisation with negative connotations), it implies the following: a higher degree of sophistication, engineering and design high-tech precision (high definition; Sheil, 2014) with minimum tolerance applied only for the intentionally included creative disruptive elements, and specific attention dedicated to all the functional-operative (performative), measuring, analytical, structural, aesthetic and production registers.

Considering the interpretations of different research fields and the constructed opposition between arts and sciences, the term instrument can be twofold. The first refers to this scientific context and high-precision machine which can provide reliable data or scientific facts, thus expressing use-value according to the procedures it performs, parameters it measures, problems it solves, and programs and protocols it follows. The second unfolds within the artistic context where it can be 
designated as a medium capable of producing and reproducing the content or an effect of a specific artistic and aesthetic value and impact, while also entailing a distinctive critical and speculative potential corresponding to the technologies by which they have been mediated. From the artistic point of view, the instrument could be interpreted as a device that enables virtuous aesthetic performance or experience and that is constitutive for certain artistic practices. Within the scientific framework, the instrument as a kind of machine has usually been translated as a control-mechanism: Wihart quotes these curious cases in which architecture-instrument comparison has been mentioned only by the medical doctors, mathematicians and physicists attached to the French Academy of Sciences and not architects (Tzonis and Lefaivre 2004:25 in Wihart, 2015:67), while architecture interpreted as an "instrument of control" (Wihart, 2015:66-677) or machine that disciplines humans and their behaviours is yet another example of the scientific approach to the problem. The way this strict and a bit scientifically "repressive" flair can be partly tamed (though scientific utility won't be abandoned) is exactly through artful calibration of the main objectives and forms of expression along with its sophisticated aesthetic and sensorial design.

Besides these oppositions, the notion of the "intelligent instrument" (Matthews, 1973) appears from the convergent scientific-artistic field. Coined during Matthews' work at the Bell Labs, it has been assigned a specific explanation within the context of his sonic experimentation as "an instrument in which you embody a certain amount of logical intelligence, such that the response you get is other than a 1:1 correspondence between your physical interaction with it and the sonic response." (Matthews in "Bell Labs \& The Origins of the Multimedia Artist" Panel, 1998). By the analogy that might elevate such definition to the level of the universal principle, a new derived explanation could be formulated as the following: an intelligent instrument is an instrument in which a certain amount or a degree of logical intelligence has been embodied in such a way that a response of the system differs from the basic 1:1 relation in the present interaction (the relation between the input information (initial impulses) and output information (system's reaction)) implying more than a mere reflection, imitation or transduction of the input values as they are (a simple change or transformation of the system as the absolute equivalent of the input parameters) and the existence of certain "thinking processes" that will alter this basic reaction and demonstrate higher cognitive performance. The instrument's machinic response, thus, includes cognition, inferencing and autonomous decision making - certain intelligence that has been inherently ascribed to the machine and that guides its behaviour - while the very term of the instrument implies high precision and quality of thereby delivered information and performance, as well as of their aesthetic and intelligible reception (experience) from the user's point of view.

In one passage about the 1950s' break that cybernetics made regarding modern epistemology (cybernetic epistemology as he calls it), Claus Pias identified this shift as "the shift from experiments to instruments, from hypothetical construction and pataphysical machines to instrumental hardware and institutionalised computer science, from speculation to explanations, from questions about the in-betweens to certainties of answers." (Pias, 2002:60 in Broeckmann, 2016:114). The second part of each transitive pair refers to something scientifically proved and applied, providing thereby explanations and answers as opposed to sheer ideation, testing, questioning and uncertainty. The instrument, thus, has been designated as a carrier of such explicative results based on and providing reliable facts; device able to perform certain tasks with precision while exhibiting firm operational qualities.

\section{CONCLUSION}

It appears that the exact term of the architecture-instrument (within the merged machinic prototype and installation typology) hasn't been so frequently, if ever so clearly used and defined, thus exhibiting the high investigative potential and the need for its better understanding. Its proposal has challenged a bit scarce resources on its particular designation (including theory, epistemology, methodology within both scientific and artistic research fields) as well as practical use and interpre- 
tations. It can be claimed that it is still underrepresented in experimental methodologies (e.g. Drawing Instruments by Kulper and Chard) while some analysis of the historical resources and uncritical deployments of the terms do not satisfy the strict scientific demands of their comprehensive study. Following these conclusions, the inquiry into the properties by which architecture-instrument can be identified and evaluated, as well as the proposal for the more elaborate analysis of its origins and interpretations, represented justifiable goals.

The exo experiment used the architecture-instrument designation to bridge the gap between the aspects of an artistic didactic and speculative device (staged in the form of an installation and certain modes of the prototype) and those of a reliable technical solution that performs demanding operations. It also aimed at merging procedures of scientific testing conducted by prototypes, and the artful critical and aesthetic analysis, performance and communication presented by installations. The format, having basic references in machinic solutions, implies properties of high-precision in production and operation, and properties of a sophisticated design focused on each detail of its structure and performance. This places it somewhere between the industrial (scientific) production (based on prototyping, versioning and optimisation design methods) and the artistic approach (highly concerned with unbiased aesthetics and critical thinking, unsusceptible to commercial preferences). They are regarded as mutually complementary methodologies enhancing each other in certain parts or rendering a greater degree of refinement in an either scientific or aesthetic register.

\section{REFERENCES}

- Ash, James, Kitchin, Rob and Agnieszka Leszczynski. 2018a. "Digital turn, digital geographies?. Progress in Human Geography, Vol. 42, No. 1, (February):25-43, Accessed July 2019. https://journals. sagepub.com/doi/10.1177/0309132516664800/http://www.heterotopiastudies.com/wp-content/uploads/2018/06/eprint.pdf

_ Benton, Tim. 1990. "Dreams of Machines: Futurism and I'Esprit Nouveau." Journal of Design History, Vol. 3, No. 1 (June):19-34. Accessed August 2, 2016. http://www.jstor.org/stable/1315719,

_ Bava, Alessandro. 2020. "Computational Tendencies." e-flux architecture (Intelligence), January 21, Accessed May 6, 2020. https://www.e-flux.com/architecture/intelligence/310405/computational-tendencies/

_ Broeckmann, Andreas. 2016. Machine Art in the Twentieth Century. Cambridge, Mass.: The MIT Press

_ Caliari, Pier Federico. 2012. "I Carnets des voyages d'Hadrien." Tractatus Logico Sintattico. La forma trasparente di Villa Adriana. Roma : Edizioni Quasar, Accessed February 2017. http://www.engramma. it/eOS2/index.php?id_articolo $=1358 \mathrm{v}$

_ Ćirić, Dragana. 2017. Scripts and Codes of Architectural Design Process: Disciplinary Borders and Transfers (Doctoral Dissertation). Belgrade: Faculty of Architecture, Belgrade University

_ Easterling, Keller. 2014. Extrastatecraft: The Power of Infrastructure. New York: Verso

_ Gardner, O. William. 2020. "Liquid Cities." Places Journal, May 2020. Accessed 26 May 2020. https:// placesjournal.org/article/liquid-cities/,

_ Goldstein, C. Seth, Campbell, D. Jason and Todd C. Mowry. 2005. "Programmable Matter." Computer, Vol. 38, No. 6, (May): 99-101.

_ Graziano, Andrea. 2016. "InFORMed matter." In Going Digital: Innovation in Art, Architecture, Science and Technology - Conference Proceedings, edited by Ružica Bogdanović, 35-43. Belgrade: STRAND Sustainable Urban Society Association

_ Headrick, R. Daniel. 2009. Technology: A World History. New York: Oxford University Press

_ Kara, Hanif and Daniel Bosia. (Eds.) 2016. Design Engineering Refocused (AD smart03). London: John Wiley \& Sons Ltd.

_ Kitchin, Rob and Martine Dodge. 2011. Code/Space. Cambridge, Mass.: The MIT Press

_ Lefèvre, Wolfgang (Ed.). 2004. Picturing Machines 1400-1700. Cambridge, Mass. and London: The MIT Press 
_ Lipson, Hod. 2011. "Self-reflective Architecture." The Cornell Journal of Architecture 8: RE, No.8 (January):16-23

- MacLennan, J. Bruce. 2015. "The Morphogenetic Path to Programmable Matter." Proceedings of the IEEE 2015, Vol. 103, No. 7, (July):1226-1232

- Magli, Giulio. 2009. "Akhet Khufu: Archaeo-astronomical Hints at the Common Project of the Two Main Pyramids of Giza, Egypt." Nexus Network Journal: Architecture, Mathematics and Astronomy in Honour of the International Year of Astronomy 2009, Vol. 11, No. 1, (April):35-50

- Menking, William. 2016. "The Museum of Applied Art delves into the ambitious, diverse career of Friedrich Kiesler." The Architect's Newspaper, July 8, 2016. Accessed December 15, 2019. https://archpaper.com/2016/07/friedrich-kiesler-life-visions-mak/\#gallery-0-slide-0

- Monti, Carlo. 2010. “ Origini e vicende del calendario occidentale." Quadrimestrale di Informazione tecnino-scientifica, n. 1/2010

- Nay, Eric. 2013. "Problematising New Technologies through Design." International Journal of Humanities and Social Science, Vol. 3, No. 5 (March): 108-114

- Negroponte, Nicholas. 1970. The Architecture Machine. Cambridge, Mass.: The MIT Press

- Negroponte, Nicholas. 1975. Soft Architecture Machines. Cambridge, Mass., London: The MIT Press

- O'Donnell, Caroline. 2013. "The Deformations of Francesco De Marchi." The Cornell Journal of architecture, 9: Mathematics, From the Ideal to the Uncertain, No.9, (March):47-59

- Packer, Randall. 2003. "The Pepsi Pavilion: Laboratory for Social Experimentation." In Future Cinema. The Cinematic Imaginary after Film, Exhibition Catalogue, edited by Jeffrey Shaw and Peter Weibel. London and Cambridge, Mass.: The MIT Press

- Rebelo Paio, Alexandra Cláudia. 2009. "Geometry, the Measure of the World." Nexus Network Journal: Architecture, Mathematics and Astronomy in Honour of the International Year of Astronomy 2009, Vol. 11, No. 1, (April):63-76

- Rondelet, Jean Baptiste and Guillaume-Abel Blouet. 1812-1814. Traité théorique et pratique de l'art de bâtir. Paris: chez l'auteur, enclos du Panthéon, ETH-Bibliothek Zürich, Rar 8949. Accessed March, 2017. http://dx.doi.org/10.3931/e-rara-45709,

- Smith, Albert. 2004. Architectural Model as Machine: A New View of Models from Antiquity to the Present Day, Oxford: Elsevier Architectural Press

- Spelling, Gert. 2015. "The "Quadrivium" in the Pantheon of Rome." In Architecture and Mathematics from Antiquity to the Future. Volume I: Antiquity to the 1500 s edited by Kim Williams and Michael J. Ostwald, 215-227, Basel: Birkhäuser

- Scaglia, Gustina. 1966. "Drawings of Machines for Architecture from the Early Quattrocento in Italy." Journal of the Society of Architectural Historians, Vol. 25, No. 2, (May):90-114. Accessed August 2, 2016, 17:58 UTC. http://www.jstor.org/stable/988375,

- Tibbits, Skylar. (Ed.) 2017. Active Matter. Cambridge, Mass.: The MIT Press

- Vee, Annette. 2017. Coding Literacy: How Computer Programming is Changing Writing. Cambridge, Mass.: The MIT Press

- Viollet-le-Duc, Eugène-Emmanuel. 1863-1872. Entretiens sur l'architecture / par Viollet-le-Duc. Paris: Morel, online archive Historical scientific literature, ETH-Bibliothek Zürich, http://dx.doi.org/10.3931/ e-rara-4694

- Wihart, Michael. 2015. The Architecture of Soft Machines (Thesis submitted to The Bartlett School of Architecture, University College London, in fulfillment of the requirements for the degree of Doctor of Philosophy (Ph.D. Architectural Design). London: Bartlett School of Architecture UCL

- Wright Steenson, Molly. 2017. Architectural Intelligence: How Designers and Architects Created a Digital Landscape. Cambridge, Mass.: The MIT Press

- Young, Liam. 2019. "Introduction. Neo-Machine: Architecture Without People." In Machine Landscapes: Architecture of the Post-Anthropocene (AD Profile 257), edited by Liam Young, 6-13. Oxford: John Wiley \& Sons

- "Bell Labs \& The Origins of the Multimedia Artist." Panel discussion produced by Art \& Science Collaborations, Inc. (ASCI), The Great Hall at The Cooper Union, New York City, November 8, 1998 (transcript courtesy of the IEEE History Center, 2014), (Organisation: Cynthia Pannucci; Participants: Emmanuel 
Ghent, Billy Kluver, Kenneth C. Knowlton, Max V. Mathews, A. Michael Noll, Laurie Spiegel, Jerry Spivack, Doree Seligmann, Carl Machover and Patty Wood), Accessed April, 2019. https://ethw.org/Archives:Bell_Labs_\%26_The_Origins_of_the_Multimedia_Artist

- 2015. Architectural Theory from the Renaissance to the Present. Koln: Taschen, Bibliotheca Universalis 